\title{
Peroxidação lipídica em cabras com anemia e doença respiratória tratadas com ferro por via parenteral ${ }^{1}$
}

\author{
Renata L. dos Santos², Rita de Cássia C.M. Botteon ${ }^{3 *}$, Paulo de Tarso L. Botteon ${ }^{3}$ \\ e Natália L. Lopes ${ }^{2}$
}

\begin{abstract}
Santos R.L., Botteon R.C.C.M., Botteon P.T.L. \& Lopes N.L. 2014. [Lipid peroxidation in goats with anemia and respiratory illness treated with parenteral iron.] Peroxidação lipídica em cabras com anemia e doença respiratória tratadas com ferro por via parenteral. Pesquisa Veterinária Brasileira 34(11):1081-1084. Departamento de Medicina e Cirurgia Veterinária, Instituto de Veterinária, Universidade Federal Rural do Rio de Janeiro, Seropédica, RJ 23890-000, Brazil. E-mail: rbotteon@ufrrj.br

Aimed to evaluate the progression of the disease and oxidative damage in goats with anemia and respiratory disease by application of parenteral iron. Six goats, adults, with anemia and respiratory disease (coughing, sneezing and nasal discharge) were studied. The control group was composed of six adults goats, healthy. The goats of both groups after undergoing clinical evaluation received similar dose $(0.5 \mathrm{~g})$ of ferric hydroxide in complex dextran intramuscularly. Blood samples collected in EDTA before the application of iron and 48 hours were taken for determination of concentration of thiobarbituric acid reactive substances (TBARS). In patients goats before the application of iron TBARS values were equivalent to the measured values in the control group before and after applying the iron $(p>0.05)$. The values measured in patients goats were significantly higher $(p<0.001)$ in the group of animals even after the application of iron and controls before and after application. The application of iron worsened the clinical condition of the animals with respiratory disease, evidencing a condition of toxicity reflected by oxidative stress. Therefore, one should not recommend to supplementation in goats with respiratory diseases.
\end{abstract}

INDEX TERMS: Oxidative stress, TBARS, pneumonia, disease, lipid peroxidation, anemia, iron, goats.

RESUMO.- Objetivou-se avaliar a progressão da doença e o dano oxidativo em cabras com anemia e doença respiratória mediante aplicação de ferro parenteral. Foram estudadas seis cabras, adultas, com parâmetros eritrocitários indicativos e anemia e manifestações de doença respiratória (tosse, espirros e secreção nasal). 0 grupo controle foi composto por seis cabras adultas, sadias. As cabras de ambos os grupos após serem submetidos à avaliação clínica recebe-

\footnotetext{
${ }^{1}$ Recebido em 7 de outubro de 2014.

Aceito para publicação em 21 de outubro de 2014.

Parte da Dissertação de Mestrado do primeiro autor no Programa de Pós-Graduação em Medicina Veterinária (PPGMV) da Universidade Federal Rural do Rio de Janeiro (UFRRJ).

${ }^{2}$ Mestranda, bolsista da Coordenação de Aperfeiçoamento de Pessoal de Nível Superior (CAPES), PPGMV, UFRRJ, Seropédica, RJ 23890-000, Brasil. E-mail: renata_lanna@hotmail.com

${ }^{3}$ Departamento de Medicina e Cirurgia Veterinária (DMCV), Instituto de Veterinária, UFRRJ, Seropédica, RJ 23890-000. E-mails: rbotteon@ufrrj.br, pbotteon@ufrrj.br; *Autor para correspondência: ritabotteon@gmail.com
}

ram dose similar $(0,5 \mathrm{~g})$ de hidróxido férrico em complexo dextrânico, por via intramuscular. Amostras de sangue colhidas com EDTA, antes da aplicação do ferro e 48 horas depois foram utilizadas para determinação da concentração de substâncias reativas ao ácido tiobarbitúrico (TBARS). Nas cabras doentes antes da aplicação do ferro os valores de TBARS foram equivalentes aos valores mensurados nos controles antes e após a aplicação do ferro $(p>0,05)$. Os valores mensurados nas cabras doentes foram muito mais elevados $(p<0,001)$ no mesmo grupo de animais depois da aplicação do ferro e nos controles antes e após a aplicação. A aplicação do ferro agravou a condição clinica dos animais com doença respiratória, sendo evidenciada uma condição de toxidade refletida pelo estresse oxidativo. Assim sendo, não se deve recomendar tal suplementação nos caprinos acometidos de doenças do aparelho respiratório.

TERMOS DE INDEXAÇÃO: Estresse oxidativo, TBARS, pneumonia, doença, peroxidação lipídica, anemia, ferro, caprinos. 


\section{INTRODUÇÃO}

Todos os organismos aeróbicos necessitam de oxigênio molecular como aceptor final de elétrons para produção eficiente de energia. Contudo, o oxigênio é um forte agente oxidante e o processo de respiração pode gerar intermediários reativos resultantes da oxidação de componentes celulares (Barbosa et al. 2010).

Espécies reativas do oxigênio (ERO) e do nitrogênio (ERN), conhecidas genericamente como radicais livres (RL), podem reagir com ácidos graxos poli-insaturados (AGPI) presentes nas membranas celulares e nas lipoproteínas iniciando uma reação em cadeia conhecida como peroxidação lipídica ou lipoperoxidação (LPO), que pode ser utilizada como indicador de dano oxidativo celular (Halliwell 2007).

0 equilíbrio entre a produção e o combate de radicais livres é fundamental para manter a integridade das estruturas moleculares (proteínas, lipídios, carboidratos, nucleotídeos), necessária para sustentar a homeostase metabólica. 0 estresse oxidativo é uma condição dinâmica caracterizada por desbalanço entre agentes pró-oxidantes e antioxidantes, com potenciais efeitos deletérios (Barreiros \& David 2006).

0 ferro além de exercer importantes funções de transporte de oxigênio no sangue e no músculo é componente de diversas enzimas relacionadas aos processos oxidativos e à proliferação celular (Hentze, Muckenthaler \& Andrews 2004). 0 acúmulo de ferro nos tecidos, células e organelas pode gerar RL e produzir danos ao DNA e ao RNA, prejudicando a síntese de proteínas, lipídeos de membrana e carboidratos; ativação de proteases e alterações na proliferação celular (Puntarulo 2005). Adicionalmente, o ferro livre pode reagir com ácidos graxos insaturados e induzir a LPO (Jurado 1997).

No Brasil, a suplementação com ferro é uma pratica comum em animais com anemia e, de acordo com Malafaia et al. (2014), ela é desnecessária aos ruminantes tratados corretamente para as hemoparasitoses. Nestas condições, tal suplementação, pode exacerbar o dano oxidativo celular e agravar o processo infeccioso visto que a maior parte dos agentes patogênicos requer ferro livre para se multiplicar (Prentice et al. 2007). Assim, objetivou-se, neste estudo, avaliar o estresse oxidativo pela suplementação de ferro parenteral em cabras com doença respiratória, bem como a progressão deste quadro.

\section{MATERIAL E MÉTODOS}

Este estudo foi aprovado Comissão de Ética no Uso de Animais (CEUA/Instituto de Veterinária, Protocolo no 005/2014).

De uma propriedade (no Recreio dos Bandeirantes, zona oeste da cidade do Rio de Janeiro), com histórico de alta mortalidade e diagnóstico positivo para Mycoplasma spp., foram estudadas seis cabras, adultas, com parâmetros eritrocitários indicativos de anemia (JAIN 1993) e manifestações de doença respiratória (tosse, espirros e secreção nasal). 0 grupo controle foi composto por seis cabras adultas, não gestantes e sem sinais de enfermidades, que apresentaram parâmetros eritrocitários e leucocitários normais.

As cabras doentes foram alojadas no Hospital Veterinário da UFRRJ (BR-465 Km 7, Seropédica, Rio de Janeiro), em baias de alvenaria, com piso cimentado e grade de madeira sobreposta, contendo bebedouro, comedouro e solário. A dieta foi constituída de uma mistura de concentrados à base de milho triturado, farelo de soja, feno de "coast-cross", capim elefante (Pennisetum purpureum) picado no cocho e capim inteiro (P. purpureum) amarrado em uma grade. 0 concentrado foi fornecido duas vezes ao dia, na base de $400 \mathrm{~g} /$ cabeça/dia. 0 feno e os capins foram oferecidos também duas vezes por dia, permitindo sobras as quais eram removidas diariamente. Os cochos, o estrado e o piso eram varridos e lavados pela manhã. Os animais foram mantidos nestas condições, sem nenhuma medicação por cinco dias. As cabras do grupo controle foram mantidas em uma propriedade localizada em Queimados, região metropolitana do Rio de Janeiro, em galpão de alvenaria com piso de madeira e com acesso ao pasto durante o dia. A alimentação era constituída de concentrado e capim $(P$. purpureum) oferecidos pela manhã e à noite.

No quinto dia, as cabras de ambos os grupos após serem submetidas ao exame clínico receberam uma dose similar $(0,5 \mathrm{~g})$ de hidróxido férrico em complexo dextrânico, por via intramuscular.

Imediatamente antes da aplicação do ferro (A) e 48 horas depois (D), foram colhidas, pela manhã, nas cabras doentes e controles, amostras de 5,0mL de sangue. Essas amostras foram colocadas em tubos a vácuo com EDTA e foram mantidas em recipientes com água e gelo, até o processamento laboratorial, em no máximo 1 hora.

No laboratório, o sangue foi dividido em alíquotas de 1,5mL, sendo uma encaminhada para o hemograma completo (analisador hematológico por impedância ${ }^{4}$ e duas acondicionadas em frascos tipo Eppendorf e centrifugadas a $1000 \mathrm{~g}$ por 10 minutos a $4^{\circ} \mathrm{C}$. O sobrenadante contendo o plasma e os leucócitos foi removido e no sedimento, foi adicionada uma solução de PBS num volume correspondente ao dobro do volume de hemácias. 0 conteúdo foi ressuspendido por inversão cuidadosa dos frascos para evitar hemólise, novamente centrifugado a $1000 \mathrm{~g}$ por 3 minutos a $4^{\circ} \mathrm{C}$. Esse procedimento foi repetido duas vezes consecutivas. Em seguida, $100 \mu \mathrm{L}$ do lavado de hemácias foi adicionado a $1900 \mu \mathrm{L}$ de água ultrapura (Milli-Q) para lise dos eritrócitos e armazenado em tubos criogênicos de $2,0 \mathrm{~mL}$ a $-80^{\circ} \mathrm{C}$ para posterior determinação da concentração de hemoglobina e substâncias reativas ao ácido tiobarbitúrico (TBARS).

A concentração de hemoglobina (em g/dL) utilizada como fator de referência para estimar as atividades enzimáticas de antioxidantes eritrocitários, foi determinada por espectrofotometria ${ }^{5}$, utilizando-se kit comercial ${ }^{6}$, segundo a recomendação do fabricante. As amostras foram analisadas em triplicata, utilizando-se as médias desses valores para estabelecer o teor de hemoglobina na amostra.

Para a determinação das TBARS utilizou-se o lisado de hemácias na proporção de 1:20. Desta solução, $1 \mathrm{~mL}$ foi pipetado em tubos plásticos de fundo cônico estéreis com capacidade de $15 \mathrm{~mL}$ acrescido de $1,0 \mathrm{~mL}$ de ácido sulfossalicílico a $3 \%$. A mistura foi agitada em vórtex por 10 segundos, centrifugada a $1000 \mathrm{~g}$ por 3 minutos e deixada em repouso por 15 minutos. Transcorrido o tempo, $500 \mu \mathrm{L}$ do sobrenadante foram pipetados para tubos de ensaio previamente identificados e acrescidos $500 \mu \mathrm{L}$ de solução de TBA $0,67 \%$. Em seguida os tubos de ensaio foram agitados por 10 segundos em vórtex e incubados em banho-maria a $80^{\circ} \mathrm{C}$ por 30 minutos. Para a leitura utilizou-se como padrão $500 \mu \mathrm{L}$ água bidestilada deionizada, acrescida de $500 \mu \mathrm{L}$ de solução de TBA a $0,67 \%$ e a amostra representada pelo sobrenadante.

Para mensurar a concentração de TBARS utilizou-se a seguin-

\footnotetext{
${ }^{4}$ PocH-100IV Diff, Sysmex.

${ }^{5}$ BioSystems A15.

${ }^{6} 11743$ - Biosystems.
} 
te equação: TBARS $=((\mathrm{D} / 0,149) \times 4) / \mathrm{Hb}) \times 1000(\mathrm{miliMol} / \mathrm{g} \mathrm{Hb})$, onde D corresponde ao valor da absorbância da amostra, 0,149 ao coeficiente de extinção do TBA ( $\mu \mathrm{Mol})$ em $535 \mathrm{~nm}$, 4 à diluição do hemolisado (1:20), Hb à concentração de hemoglobina no hemolisado (g/dL) e 1000 ao fator de conversão de microMol (proveniente do coeficiente de extinção) para miliMol.

Os resultados foram submetidos ao teste de T-Student a 5\% de significância em relação aos momentos (antes e depois) e categorias (doentes e controles).

\section{RESULTADOS E DISCUSSÃO}

Clinicamente observou-se após aplicação do ferro uma exacerbação dos sinais de doença respiratória (tosse, secreção nasal catarral e estertores pulmonares), sem variação do estado geral e ocorrência de febre. Os animais controles não apresentaram nenhuma alteração clínica evidente, mantendo-se aparentemente normais. A resposta clínica ao aporte de ferro no grupo doente justifica-se pela disponibilidade maior de ferro para as atividades metabólicas microbianas, como indicado por Messenger \& Barclay (1983).

Como demonstrado no Quadro 1, nas cabras doentes antes da aplicação do ferro os valores de TBARS foram equivalentes aos valores mensurados nos controles antes e após a aplicação do ferro ( $\mathrm{p}>0,05)$. Por outro lado, os valores mensurados nas cabras doentes foram muito mais elevados $(\mathrm{p}<0,001)$ quando comparados ao mesmo grupo de animais no momento anterior à aplicação e controles antes e após a aplicação (Quadro 1). Destaca-se que nos controles os níveis de TBARS após aplicação do ferro elevaram-se apenas ligeiramente mantendo-se estáveis. Valores de TBARS equivalentes indicam um efeito menos expressivo do ferro sobre o metabolismo oxidativo nos animais sem sinais de enfermidades, comparativamente aqueles com doença clinicamente aparente.

Não existem valores de referência deste metabólito para os caprinos; porém, já foi demonstrado que a suplementação com selênio e vitamina E reduz a atividade oxidativa resultando em menores concentrações de TBARS no sangue desses animais (Sönmez et al. 2009, Guimarães et al. 2011). Nicolodi et al. (2010) relataram que não há influência da suplementação com selênio e vitamina E no perfil proteico e metabolismo oxidativo quando os cordeiros se encontram severamente parasitados por Haemonchus contortus.

Quadro 1. Média, desvio padrão, valores máximos e mínimos de espécies reativas ao ácido tiobarbitúrico (TBARS) no soro de cabras anêmicas com doença respiratória (doentes) e sem sinais de enfermidades (controles) antes e 48 horas depois da aplicação de hidróxido férrico em complexo dextrânico $(0,5 g)$, por via intramuscular

\begin{tabular}{lcccc}
\hline & $\begin{array}{c}\text { Doentes } \\
\text { Antes }\end{array}$ & $\begin{array}{c}\text { Doentes } \\
\text { Depois }\end{array}$ & $\begin{array}{c}\text { Controles } \\
\text { Antes }\end{array}$ & $\begin{array}{c}\text { Controles } \\
\text { Depois }\end{array}$ \\
\hline Média & $890^{\mathrm{a}}$ & $4180^{\mathrm{b}}$ & $732^{\mathrm{a}}$ & $803^{\mathrm{a}}$ \\
Desvio padrão & 538 & 2754 & 139 & 410 \\
Mínimo & 298 & 1926 & 556 & 524 \\
Máximo & 1826 & 8593 & 915 & 1594
\end{tabular}

Na linha de médias, números seguidos de letras diferentes indicam diferença significativa a $99 \%(\mathrm{p}<0,01)$.
Pelos resultados pode-se sugerir que o excesso de ferro livre atuou sobre o processo infeccioso promovendo clinicamente uma exacerbação da doença com aumento da peroxidação lipídica justificada pela ação oxidante do ferro na presença de oxigênio necessário aos organismos aeróbios para produção de energia como sugerido por Boelaert (1996), Prentice et al. (2007) e Barbosa et al. (2010).

De acordo com Beconi et al. (1991), os níveis de TBARS podem ser influenciados pela quantidade de células susceptíveis à peroxidação lipídica, e neste caso o ferro aplicado por via intramuscular nos animais com doença respiratória refletiu no perfil de estresse oxidativo sistêmico com altos níveis de TBARS após a suplementação.

Segundo Carvalho et al. (2006), é provável que a anemia em quadros de infecção/inflamação possa ser considerada como um mecanismo de defesa, não específico, em resposta do hospedeiro à invasão microbiana.

Rocha et al. (2007) demonstraram que a suplementação oral de ferro foi efetiva em aumentar a resposta eritropoiética em cordeiros anêmicos. No entanto houve um aumento na peroxidação dos lipídios de membrana do eritrócito em cordeiros suplementados com doses altas de ferro injetável, similares aos resultados obtidos por Knutson et al. (2000) após aplicação de ferro oral em ratos e corroboram os dados obtidos no presente estudo.

Rocha et al. (2012) concluíram que a suplementação com diferentes formas de ferro oral resulta em estresse oxidativo sem diferença entre os grupos na mensuração de ferro sérico apesar dos níveis de suplementação mais altos que a recomendação diária para a espécie. Isto pode ser explicado de acordo com Oats (2007) pelo mecanismo de homeostasia do ferro, onde a absorção duodenal e a excreção fecal são reguladas pela necessidade do organismo, de modo a evitar o acúmulo tóxico.

Sobre o papel do ferro na patogenicidade de bactérias, Messenger \& Barclay (1983) relataram que a adição de ferro, a um animal infectado parece aumentar a extensão da infecção por uma variedade de bactérias, sendo importante a maneira pela qual o ferro é administrado. Após a administração o ferro deve ser capaz de se difundir para o local da infecção. Dessa forma, a administração oral é menos relevante para o favorecimento das bactérias. De acordo com Hoffbrand et al. (2004) o ferro aplicado por via parenteral, deve ser removido da circulação para evitar seu acúmulo não ligado à transferrina ou à ferritina. 0 ferro que excede a capacidade de transporte da transferrina causa danos às membranas celulares, resultando em estresse oxidativo, como evidenciado neste estudo.

Rocha (2005) ao avaliar o status oxidativo e a recuperação do quadro hematológico de cordeiros com anemia induzida por sangramento e suplementados ou não com ferro observou aumento nos valores de TBARS. Naquele caso os animais estavam com anemia, mas não apresentavam infecção como no presente estudo. 0 autor sugeriu a possibilidade de utilização de ferro como tratamento auxiliar para verminose junto com anti-helmínticos, contrariando as evidências do efeito adverso do ferro (Tlieu et al. 2001, Crichton et al. 2002, Puntarulo 2005, McDermid \& Prentice 2006, Sazawal et al. 2006). 


\section{CONCLUSÕES}

A aplicação do ferro agravou a condição clinica dos animais, sendo evidenciada uma condição de toxidade refletida pelo estresse oxidativo.

$\mathrm{O}$ uso de ferro mesmo em condições de anemia em animais com doenças infecciosas é contra indicado, pelo potencial agravamento da condição clínica e estresse oxidativo.

Resultados de estudos sobre a suplementação de ferro são conflitantes. Assim, é importante estabelecer a segurança da suplementação em animais sadios e enfermos.

\section{REFERÊNCIAS}

Barbosa K.B.F., Costa N.M.B., Alfenas R.C.G., Paula S.O., Minim V.P.R. \& Bressan J. 2010. Estresse oxidativo: conceito, implicações e fatores modulatórios. Revta Nutr. 23(4):629-643.

Barreiros A.L.B. \& David J.M. 2006. Estresse Oxidativo: relação entre geração de espécies reativas e defesa do organismo. Quim. Nova 29(1):113123.

Beconi M.T., Affranchino M.A., Schang L.M. \& Beorlegui N.B. 1991. Influence of antioxidants on SOD activity in bovine sperm. Biochem. J. 23(3):545-553.

Boelaert J.R. 1996. Iron and infection. Acta Clin. Belg. 51:213-221.

Carvalho M.C., Baracat E.C.E. \& Sgarbieri V.C. 2006. anemia ferropriva e anemia de doença crônica: distúrbios do metabolismo de ferro. Segur. Alim. Nutr. 13(2):54-63.

Crichton R.R., Wilmet S., Legssyer R. \& Ward R.J. 2002. Molecular and cellular mechanisms of iron homeostasis and toxicity in mammalian cells. J. Inorg. Biochem. 91:09-18.

Guimarães J.A., Xavier G.C., Soares P.C., Dantas A.C., Soares F.A.P., Mendonça C.L., Guerra M.M.P. \& Silva Júnior V.A. 2011. Perfil de marcadores do estresse oxidativo em caprinos suplementados ou não com selênio e vitamina E e submetidos à insulação escrotal. Semina, Ciênc. Agrárias 32(1):1955-1964.

Halliwell B. 2007. Biochemistry of oxidative stress. Bioch. Soc. Transact. 35(5):1147-1150.

Hentze W.M., MuCkenthaler M.U. \& Andrews N.C. 2004. Balancing acts: molecular control of mammalian iron metabolism. Cell 117:285-297.

Hoffbrand A.V., Pettit J.E. \& Moss P.A.H. 1993. Fundamentos em hematologia. $4^{\mathrm{a}}$ ed. Artmed, São Paulo, 2004. 358p.

Jain N.C. 1993. Essentials of veterinary hematology. Lea and Febiger, Philadelphia. $417 \mathrm{p}$.

Jurado R.L. 1997. Iron, infections, and anemia of inflammation. Clin. Infect. Dis. 25:888-895.

Knutson M.D., Oukka M., Koss L.M., Aydemir F. \& Wessling-Resnick M. 2005. Iron release from macrophages after erythrophagocytosis is up-regulated by ferroportin 1 overexpression and down-regulated by hepcidin. Proc. Natl Acad. Sci. USA 102:1324-1328.

Lieu P.T., Heiskala M., Peterson P.A. \& Yang Y. 2001. The roles of iron in health and disease. Mol. Aspects Med. 22(1):81-87.

Malafaia P., Magnoli Costa R., Brito M.F., Peixoto P.V., Barbosa J.D., Tokarnia C.H. \& Döbereiner J. 2014. Equívocos arraigados no meio pecuário sobre deficiências e suplementação minerais em bovinos no Brasil. Pesq. Vet. Bras. 34(3):244-49.

McDermid J.M. \& Prentice A.M. 2006. Iron and infection: effects of host iron status and the iron-regulatory genes haptoglobin and NRAMP1 (SLC11A1) on host-pathogen interactions in tuberculosis and HIV. Clin. Sci. 110:503-524.

Messenger A.J. \& Barclay R. 1983. Bacteria, iron and pathogenicity. Biochem. Educ. 11(2):54-63.

Nicolodi P.R.S.J., Camargo E.V., Zeni D., Rocha R.X., Cyrillo F.C., Souza F.N., Della Libera A.M.M., Bondan C. \& Leal M.L.R. 2010. Perfil proteico e metabolismo oxidativo de cordeiros experimentalmente infectados pelo Haemonchus contortus e suplementados com selênio e vitamina E. Ciência Rural 40(3):561-567.

Oats P.S. 2007. The role of hepcidin and ferroportin in iron absorption. Histol. Histopathol. 22(7):791-804.

Prentice A.M., Ghattas H. \& Cox S.E. 2007. Host-pathogen interactions: can micronutrients tip the balance? J. Nutr. 37:1344-1347.

Puntarulo S. 2005. Iron oxidative stress and human health. Mol. Aspects Med. 26(4/5):299-312.

Rocha R.X. 2005. Eritrograma e estresse oxidativo em cordeiros anêmicos tratados com ferro dextrano. Dissertação de Mestrado em Medicina Veterinária, Universidade Federal de Santa Maria, Santa Maria, RS. 39p. Disponível em <http://coralx.ufsm.br/ppgmv/ricardo_xavier.pdf> Acesso em 10 set. 2013.

Rocha R.X., Bondan C., Marinho R., Lopes S.T.A. \& Cecim M. 2007. Dextran iron in anemic lambs: effects on reticulocytosis and free radical production. Ciênc. Rural 37(5):1344-1348.

Rocha R.X., Camargo E.V., Zeni D., Nicolodi P.R.S., Leal M.R.L. \& Cecim M.S. 2012. Eritrograma, estresse oxidativo e interação mineral em cordeiros naturalmente infectados por parasitas gastrintestinais suplementados com diferentes formas de ferro oral. Semina, Ciênc. Agrárias 33(2):723730 .

Sazawal S., Black R.E., Ramsan M., Chwaya H.M., Stoltzfus R.J., Dutta A., Dhingra U., Kabole I. \& Deb S. 2006. Effects of routine prophylactic supplementation with iron and folic acid on admission to hospital and mortality in preschool children in a high malaria transmission setting: community-based, randomised, placebo-controlled trial. Lancet 367:133-143.

Sherman A.R. 1992. Zinc, copper, and iron nutriture and immunity. J. Nutr. 122:604-609.

Sönmez M., Bozkurta T., Türka G., Güra S., Kizilb M. \& Yüceb A. 2009. The effect of vitamin $E$ treatment during preovulatory period on reproductive performance of goats following estrous synchronization using intravaginal sponges. Anim. Reprod. Sci. 114(1/3):183-192. 